\title{
Achromobacter insolitus sp. nov. and Achromobacter spanius sp. nov., from human clinical samples
}

\author{
Tom Coenye, ${ }^{1}$ Marc Vancanneyt, ${ }^{2}$ Enevold Falsen, ${ }^{3}$ Jean Swings ${ }^{2}$ \\ and Peter Vandamme ${ }^{1}$ \\ 1,2 Laboratorium voor Microbiologie ${ }^{1}$ and BCCM/LMG Bacteria Collection², Universiteit Gent,
Gent, Belgium \\ ${ }^{3}$ CCUG Culture Collection, University of Göteborg, Göteborg, Sweden
}

Correspondence

Tom Coenye

Tom.Coenye@ugent.be

\begin{abstract}
A polyphasic taxonomic study (employing whole-cell protein and fatty acid analyses, 16S rDNA sequencing, DNA-DNA hybridization, determination of DNA G $+C$ content, antibiotic susceptibility testing and extensive phenotypic characterization) was performed on 10 isolates that appeared to be related to Alcaligenes faecalis. The isolates were recovered from diverse environments that included human clinical samples. 16S rDNA sequence analysis indicated that these isolates belonged to the genus Achromobacter. Whole-cell protein analysis distinguished two groups, which were confirmed by DNA-DNA hybridization. Based on the results of this study, the organisms were classified as two novel Achromobacter species, Achromobacter insolitus sp. nov. (type strain, LMG $6003^{\mathrm{T}}$ ) and Achromobacter spanius sp. nov. (type strain, LMG 5911 ${ }^{\mathrm{T}}$ ). Achromobacter insolitus can be distinguished from Achromobacter spanius by its ability to grow on acetamide and to assimilate mesaconate and aconitate, and by its inability to assimilate diaminobutane. Various tests allow the differentiation of both novel species from other Achromobacter species, including growth on acetamide, denitrification and assimilation of D-glucose, D-xylose, mesaconate, aconitate and diaminobutane.
\end{abstract}

The genus Achromobacter was described by Yabuuchi \& Yano (1981) and originally contained a single species, Achromobacter xylosoxidans. Following a polyphasic taxonomic study, Yabuuchi et al. (1998) transferred the species Alcaligenes ruhlandii and Alcaligenes piechaudii to the genus Achromobacter. The same authors also transferred Alcaligenes denitrificans to the genus Achromobacter as Achromobacter xylosoxidans subsp. denitrificans. However, the reclassification of Alcaligenes denitrificans as a subspecies of Achromobacter xylosoxidans contradicts previous work that showed that there is sufficient evidence to consider both taxa as distinct species (Vandamme et al., 1996). We recently proposed to formally reclassify Alcaligenes denitrificans as Achromobacter denitrificans (Coenye et al., 2003). Achromobacter xylosoxidans is widespread in aquatic habitats, but has also been involved in opportunistic infection of humans (Kersters \& De Ley, 1984). For example,

\footnotetext{
The GenBank/EMBL/DDBJ accession numbers for the 16S rRNA gene sequences of strains LMG $6003^{\top}$ and LMG $5911^{\top}$ are AY170847 and AY170848, respectively.

A picture of the protein profiles of Achromobacter spanius and Achromobacter insolitus strains and tables showing their fatty acid compositions and $\mathrm{MIC}$ values are available as supplementary material in IJSEM Online.
}

Achromobacter xylosoxidans is capable of causing persistent respiratory tract infection in cystic fibrosis patients (Liu et al., 2002). Achromobacter piechaudii can be isolated from soil and human clinical samples, including blood (Kiredjian et al., 1986), whereas Achromobacter ruhlandii is a soil commensal that is not known to be pathogenic to humans (Kersters \& De Ley, 1984).

We performed a polyphasic taxonomic study to elucidate the taxonomic positions of 10 isolates that were recovered from diverse environments, including human clinical samples. These isolates resembled Alcaligenes faecalis phenotypically, but whole-cell protein and fatty acid analyses suggested that they belonged to the genus Achromobacter. We show that these isolates belong to two novel Achromobacter species, for which we propose the names Achromobacter insolitus sp. nov. and Achromobacter spanius sp. nov.

Strains used in this study are listed in Table 1. Reference strains of other taxa have been described previously (Vandamme et al., 1995, 1996; Foss et al., 1998; Yabuuchi et al., 1998; Coenye et al., 2003). All strains were grown aerobically on trypticase soy agar (TSA; BBL) at $37^{\circ} \mathrm{C}$ unless indicated otherwise. For SDS-PAGE of whole-cell proteins, strains were grown on TSA for $48 \mathrm{~h}$ at $37^{\circ} \mathrm{C}$. 
Table 1. List of strains studied

API, Appareils et Procédés d'Identification, Montalieu-Vercieu, France; CCUG, Culture Collection, University of Göteborg, Göteborg, Sweden; LMG, BCCM/LMG Bacteria Collection, Laboratorium voor Microbiologie, Gent, Belgium.

\begin{tabular}{|c|c|c|}
\hline Species and strain designation & Depositor & Source \\
\hline \multicolumn{3}{|l|}{ Achromobacter insolitus: } \\
\hline LMG 5997 (=CCUG 47056=Gilardi 3599=API 195-3-84) & D. Monget & Laboratory sink \\
\hline LMG $6003^{\mathrm{T}}\left(=\right.$ CCUG $47057^{\mathrm{T}}=$ Gilardi $3038^{\mathrm{T}}=$ API $\left.201-3-84^{\mathrm{T}}\right)$ & D. Monget & Leg wound \\
\hline LMG $6000(=$ CCUG $47058=$ Gilardi $3401=$ API 198-3-84 $)$ & D. Monget & Urine \\
\hline LMG 5999 (=CCUG 47059= Gilardi 3505=API 197-3-84) & D. Monget & Wound \\
\hline LMG $6001(=$ CCUG $47060=$ Gilardi $3370=$ API $199-3-84)$ & D. Monget & \\
\hline LMG 6010 (=CCUG 47061= Gilardi 4207=API 72-4-82) & D. Monget & \\
\hline \multicolumn{3}{|l|}{ Achromobacter spanius: } \\
\hline LMG 14525 (=CCUG 24722=Gilardi 5347) & G. L. Gilardi & \\
\hline LMG $5911^{\mathrm{T}}\left(=\right.$ CCUG $47062^{\mathrm{T}}=$ API $\left.198-2-84^{\mathrm{T}}\right)$ & D. Monget & Blood \\
\hline LMG 5896 (=CCUG 47063=API 151-2-84) & D. Monget & \\
\hline LMG 5909 (=CCUG $47064=$ API 187-2-84) & D. Monget & \\
\hline
\end{tabular}

Preparation of whole-cell proteins and SDS-PAGE were performed as described previously (Pot et al., 1994). Densitometric analysis, normalization and interpolation of protein profiles and numerical analysis with the Pearson product-moment correlation coefficient were performed by using GelCompar 4.2 software (Applied Maths). Sequences of the 16S rRNA genes of strains LMG $6003^{\mathrm{T}}$ and LMG $5911^{\mathrm{T}}$ were determined as described previously (Coenye et al., 1999). Phylogenetic and bootstrap analyses (1000 replicates) were performed by using Kodon software (Applied Maths); a phylogenetic tree was constructed by using the neighbour-joining method (Saitou \& Nei, 1987). Preparation of high-molecular-mass DNA for DNA-DNA hybridization experiments and determination of the degree of DNA-DNA binding by the initial renaturation rate method were performed as described previously (De Ley et al., 1970; Vandamme et al., 1992). Each value is the mean of at least two hybridization experiments. Total DNA concentration was $65 \mu \mathrm{g} \mathrm{ml}^{-1}$ and the optimal renaturation temperature in $2 \times$ SSC $(1 \times$ SSC: $0 \cdot 15 \mathrm{M}$ $\mathrm{NaCl}, 0.015 \mathrm{M}$ sodium citrate, $\mathrm{pH} 7 \cdot 0$ ) was $79^{\circ} \mathrm{C}$. Alternatively, high-molecular-mass DNA was prepared as described by Pitcher et al. (1989) and DNA-DNA hybridization was performed with photobiotin-labelled probes in microplate wells as described by Ezaki et al. (1989), using an HTS 7000 BioAssay Reader (PerkinElmer) for fluorescence measurements. Hybridization temperature was $50^{\circ} \mathrm{C}$. Reciprocal experiments were performed for every pair of strains. For determination of DNA base composition, DNA (prepared as described above) was degraded enzymically into nucleosides as described by Mesbah et al. (1989). The nucleoside mixture was then separated by HPLC, using a Waters SymmetryShield C8 column thermostatted at $37^{\circ} \mathrm{C}$. The solvent was $0.02 \mathrm{M} \mathrm{NH}_{4} \mathrm{H}_{2} \mathrm{PO}_{4}(\mathrm{pH} 4 \cdot 0)$ with $1.5 \%$ acetonitrile. Non-methylated $\lambda$-phage DNA (Sigma) was used as the calibration reference. After $24 \mathrm{~h}$ incubation at $35^{\circ} \mathrm{C}$, a loopful of well-grown cells was harvested; fatty acid methyl esters were prepared as described previously
(Vandamme et al., 1992) and separated and identified by using the Sherlock Microbial Identification system (version 3.0; MIDI). API galleries (API 50CH, API 50AO and API 50AA; bioMérieux) were used to determine assimilation of 147 organic compounds as sole carbon sources, as described previously (Kersters et al., 1984). Classical phenotypic tests were performed as described previously (Vandamme et al., 1993). API 20NE and API ZYM tests were performed according to the recommendations of the manufacturer (bioMérieux). MIC values towards levofloxacin, ciprofloxacin, ofloxacin, sparfloxacin, erythromycin, roxithromycin, clarithromycin, azithromycin, cefotaxime, cefpirome and rifampicin were determined for all strains listed in Table 1 by using the agar dilution method, conforming to NCCLS (1995) guidelines. Strains were grown on Mueller-Hinton agar (BRL) for $16-20 \mathrm{~h}$ at $35^{\circ} \mathrm{C}$.

Reproducibility of SDS-PAGE of whole-cell proteins was checked by preparing protein extracts in duplicate. The correlation level between patterns was $>93 \%$ (data not shown). After numerical analysis and visual comparison, two clusters could be delineated, whilst reference strains of other Achromobacter and Alcaligenes species occupied separate positions in the dendrogram (Fig. 1). One cluster contained Achromobacter spanius LMG 5896, LMG 14525, LMG 5911 ${ }^{\mathrm{T}}$ and LMG 5909. Achromobacter insolitus strains LMG 5997, LMG 6000, LMG 5999, LMG 6003 ${ }^{\mathrm{T}}$, LMG 6010 and LMG 6001 formed the second cluster. The protein patterns of strains in both clusters were also clearly different from those of Bordetella and Kerstersia strains (data not shown). The $16 \mathrm{~S}$ rDNA sequences of isolates LMG $5911^{\mathrm{T}}$ and LMG $6003^{\mathrm{T}}$ (representatives of the two proteinelectrophoretic groups) were determined and compared with available $16 \mathrm{~S}$ rDNA sequences of other $\beta$-Proteobacteria (Fig. 2). The $16 \mathrm{~S}$ rDNA sequences of LMG $5911^{\mathrm{T}}$ and LMG $6003^{\mathrm{T}}$ were very similar to each other $(98 \cdot 3 \%$ similarity) and were related closely to those of Achromobacter piechaudii (98.6 and $98.0 \%$ similarity, respectively), Achromobacter 


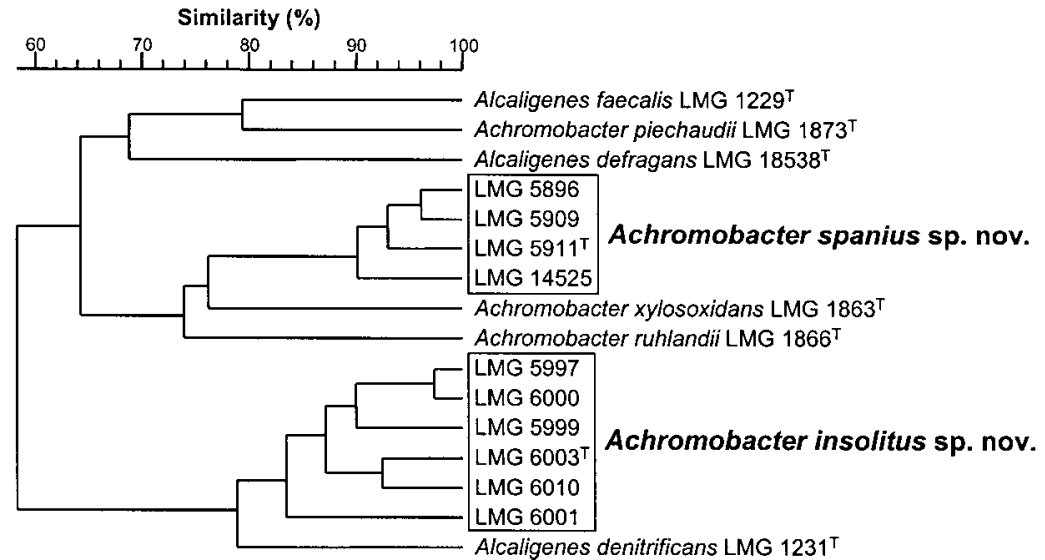

Fig. 1. Dendrogram derived from UPGMA linkage of correlation coefficients between protein patterns of strains studied. Correlation coefficient is expressed as percentage similarity for convenience. ruhlandii (98.0 and $98.5 \%$, respectively), Achromobacter xylosoxidans (98.1 and $98 \cdot 4 \%$, respectively) and Achromobacter denitrificans $(97 \cdot 6$ and $98.0 \%$, respectively). Bootstrap analysis indicated that strains LMG $5911^{\mathrm{T}}$ and LMG $6003^{\mathrm{T}}$ formed a stable phylogenetic group with other Achromobacter species (bootstrap value, 99.9\%).

As $16 \mathrm{~S}$ rDNA sequence similarity of representative isolates of both protein-electrophoretic groups was well above $97 \%$, DNA-DNA hybridization was performed to further clarify their relatedness (Stackebrandt \& Goebel, 1994). DNA was prepared from isolates LMG $6003^{\mathrm{T}}$, LMG 6001, LMG 6010, LMG 6000 and LMG $5911^{\mathrm{T}}$ and from reference strains of Achromobacter piechaudii, Achromobacter xylosoxidans, Achromobacter denitrificans, Achromobacter ruhlandii, Alcaligenes faecalis, Bordetella hinzii and Kerstersia gyiorum. DNA binding values are shown in Table 2; they confirm that strains from both electrophoretic groups formed two separate novel Achromobacter species. The DNA $\mathrm{G}+\mathrm{C}$ content of isolates LMG $6003^{\mathrm{T}}$, LMG 6001, LMG 6010, LMG 6000 and LMG $5911^{\mathrm{T}}$ was $64 \cdot 9,65 \cdot 3,64 \cdot 9,65 \cdot 5$ and $64.9 \mathrm{~mol} \%$, respectively.
Cellular fatty acid compositions of all isolates of Achromobacter spanius and Achromobacter insolitus were determined. Fatty acid compositions of other Achromobacter species and of Alcaligenes faecalis were available from previous studies (Coenye et al., 2003). Predominant fatty acids that were present in both novel Achromobacter species were $\mathrm{C}_{16: 0}, \mathrm{C}_{17: 0}$ cyclo, summed feature 2 (comprising $\mathrm{C}_{14: 0}$ $3-\mathrm{OH}$, iso- $\mathrm{C}_{16: 1} \mathrm{I}$, an unidentified fatty acid with equivalent chain-length of 10.928 and/or $\mathrm{C}_{12: 0}$ ALDE) and summed feature 3 (comprising $\mathrm{C}_{16: 1} \omega 7 c$ and/or iso- $\mathrm{C}_{15: 0} 2-\mathrm{OH}$ ). Detailed results of the fatty acid composition analysis are available as supplementary material in IJSEM Online.

All strains examined showed oxidase, catalase, $\mathrm{C}_{4}$-esterase and leucine arylamidase activities but no lysine decarboxylase, ornithine decarboxylase, arginine dihydrolase, gelatinase, amylase, $\beta$-galactosidase or DNase activity. All strains were capable of growth between 28 and $37^{\circ} \mathrm{C}$ and could grow at $\mathrm{NaCl}$ concentrations from 0 to $4 \cdot 5 \%$. All strains reduced nitrate but none reduced nitrite or were capable of denitrification. No haemolysis, hydrolysis of aesculin or production of indole, $\mathrm{H}_{2} \mathrm{~S}$ or acid on TSI agar was observed.

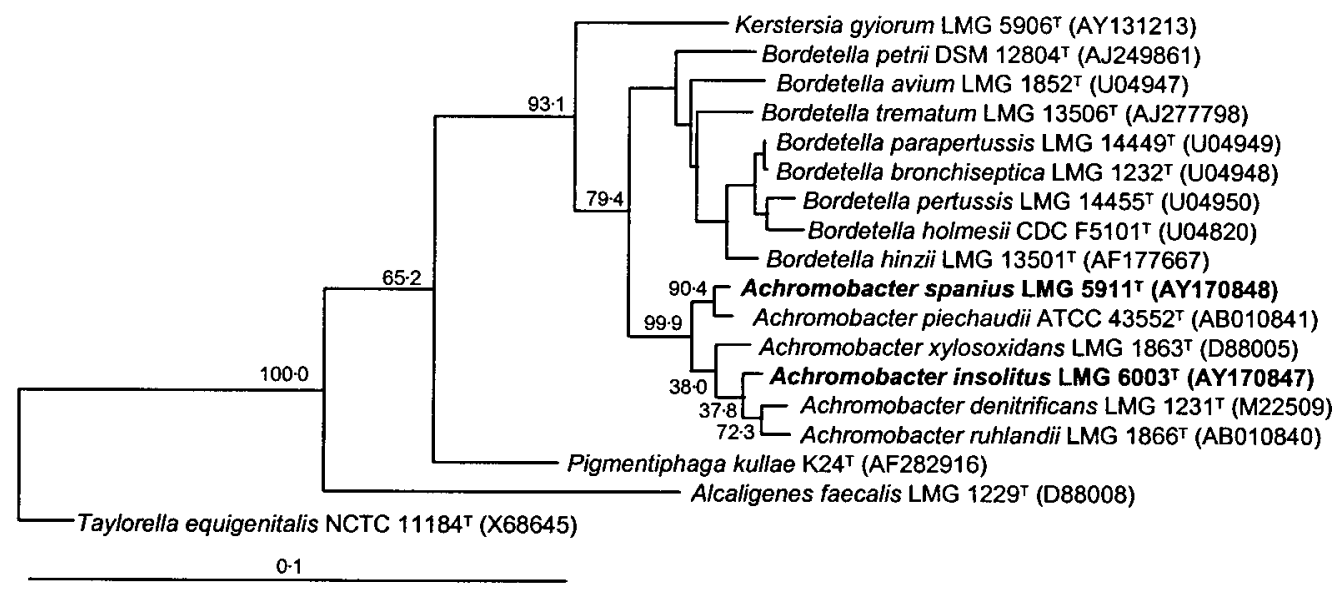

Fig. 2. Phylogenetic tree (based on $16 \mathrm{~S}$ rDNA sequences) showing positions of $A$. insolitus and $A$. spanius. Bar, $10 \%$ sequence dissimilarity. 
Table 2. DNA-DNA binding values (\%) of all strains examined

\begin{tabular}{|c|c|c|c|c|c|}
\hline \multirow[t]{2}{*}{ Strain } & \multicolumn{5}{|c|}{ DNA binding values with strain: } \\
\hline & 1 & 2 & 3 & 4 & 5 \\
\hline 1. Achromobacter insolitus LMG $6003^{\mathrm{T}}$ & 100 & & & & \\
\hline 2. Achromobacter insolitus LMG 6001 & & 100 & & & \\
\hline 3. Achromobacter insolitus LMG 6010 & $76^{*}$ & & 100 & & \\
\hline 4. Achromobacter insolitus LMG 6000 & $89^{*}$ & $78^{\star}$ & & 100 & \\
\hline 5. Achromobacter spanius LMG $5911^{\mathrm{T}}$ & 44 & $6^{*}$ & $18^{*}$ & $21^{\star}$ & 100 \\
\hline 6. Achromobacter piechaudii LMG $1873^{\mathrm{T}}$ & 33 & & & & 47 \\
\hline 7. Achromobacter xylosoxidans LMG $1863^{\mathrm{T}}$ & 34 & & & & 36 \\
\hline 8. Achromobacter denitrificans LMG $1231^{\mathrm{T}}$ & 42 & & & & 34 \\
\hline 9. Achromobacter ruhlandii LMG $1866^{\mathrm{T}}$ & 35 & & & & 42 \\
\hline 10. Alcaligenes faecalis LMG $1229^{\mathrm{T}}$ & 4 & & & & 7 \\
\hline 11. Bordetella hinzii $\mathrm{LMG} 13501^{\mathrm{T}}$ & 18 & & & & 25 \\
\hline 12. Kerstersia gyiorum LMG $5906^{\mathrm{T}}$ & 9 & & & & 12 \\
\hline
\end{tabular}

${ }^{\star}$ Values obtained with the initial renaturation rate method; other values were obtained with the microplate method.

Growth was never observed on $10 \%$ lactose, Tween 80 or oxidation-fermentation (OF) medium supplemented with glucose, maltose, adonitol, fructose or xylose. $\mathrm{C}_{8}$-esterlipase, $\mathrm{C}_{14}$-lipase, valine arylamidase, cysteine arylamidase, trypsin, chymotrypsin, phosphoamidase, $\alpha$-galactosidase, $\beta$-glucuronidase, $\alpha$-glucosidase, $\beta$-glucosidase, $N$-acetyl- $\beta$ glucosaminidase, $\alpha$-mannosidase and $\alpha$-fucosidase activities were never observed. All strains assimilated the following substrates: gluconate, acetate, propionate, butyrate, isobutyrate, $n$-valerate, succinate, fumarate, adipate, pimelate, suberate, azelate, sebacate, DL-lactate, DL-3-hydroxybutyrate, D-malate, L-malate, meso-tartrate, pyruvate, citraconate, itaconate, citrate, phenylacetate, $m$-hydroxybenzoate, $\mathrm{D}$ - $\alpha$-alanine, L- $\alpha$-alanine, L-leucine, L-isoleucine, L-serine, L-threonine, L-phenylalanine, L-histidine, L-aspartate, L-glutamate, L-proline, DL-4-aminobutyrate and 2-aminobenzoate. None of the strains assimilated the following substrates: glycerol, erythritol, D-arabinose, L-arabinose, ribose, D-xylose, L-xylose, adonitol, methyl $\beta$-D-xyloside, galactose, D-glucose, D-fructose, D-mannose, L-sorbose, L-rhamnose, dulcitol, inositol, mannitol, sorbitol, methyl $\alpha$-D-mannoside, methyl $\alpha$-D-glucoside, $N$-acetylglucosamine, amygdalin, arbutin, aesculin, salicin, cellobiose, maltose, lactose, melibiose, sucrose, trehalose, inulin, D-melezitose, raffinose, starch, glycogen, xylitol, $\beta$-gentiobiose, D-turanose, D-lyxose, D-tagatose, D-fucose, L-fucose, D-arabitol, L-arabitol, 2-ketogluconate, 5-ketogluconate, caprylate, oxalate, malonate, glycolate, levulinate, $o$-hydroxybenzoate, D-mandelate, L-mandelate, phthalate, isophthalate, terephthalate, trigonelline, L-arginine, betaine, creatine, DL-5-aminovalerate, 2-aminobenzoate, 3-aminobenzoate, 4-aminobenzoate, urea, acetamide, sarcosine, ethylamine, butylamine, amylamine, ethanolamine, benzylamine, spermine, histamine or glucosamine. Urease activity, growth on acetamide and assimilation of isovalerate, $n$-caproate, heptanoate, pelargonate, caprate, malate, glutarate, DLglycerate, D-tartrate, L-tartrate, 2-oxoglutarate, mesaconate, aconitate, benzoate, $p$-hydroxybenzoate, glycine, L-norleucine, L-valine, DL-norvaline, DL-2-aminobutyrate, L-cysteine, L-methionine, L-tyrosine, D-tryptophan, L-tryptophan, Lornithine, L-lysine, L-citrulline, DL-kynurenine, $\beta$-alanine, DL-3-aminobutyrate, diaminobutane and tryptamine were strain-dependent characteristics.

The range of $\mathrm{MIC}$ values and $\mathrm{MIC}_{50}$ and $\mathrm{MIC}_{90}$ of the strains are available as supplementary data in IJSEM Online.

Previous studies have indicated that SDS-PAGE of wholecell proteins is a valuable tool for identification of members of the family Alcaligenaceae (Vancanneyt et al., 1995; Vandamme et al., 1995, 1996; Coenye et al., 2003). By using whole-cell protein analysis, both Achromobacter insolitus and Achromobacter spanius could be differentiated easily from each other, from known Achromobacter species and from members of the genera Alcaligenes, Bordetella and Kerstersia (Fig. 1 and data not shown). Both quantitative and qualitative differences occur in the fatty acid compositions of different Achromobacter species; however, these differences are small and it seems questionable whether they will suffice to identify strains at the species level. Biochemically, both novel Achromobacter species are difficult to separate from each other, from other Achromobacter species and from Alcaligenes faecalis. Biochemical characteristics that are useful for the differentiation of Achromobacter insolitus and Achromobacter spanius from each other and from other Achromobacter species are given in Table 3. In addition, differentiation of Achromobacter insolitus and Achromobacter spanius from Alcaligenes faecalis is possible due to the absence of assimilation of azelate, $\mathrm{D}$-malate and adipate in the latter. 
Table 3. Phenotypic characteristics that are useful for the differentiation of $A$. insolitus and $A$. spanius from other Achromobacter species

Taxa: 1, A. insolitus; 2, A. spanius; 3, A. xylosoxidans; 4, A. denitrificans; 5, A. piechaudii; 6, A. ruhlandii. +, Positive; -, negative; $\mathrm{V}$, strain-dependent; ND, not determined. Data for taxa 3-6 were taken from Kersters \& De Ley (1984), Yabuuchi et al. (1998) and our own unpublished data.

\begin{tabular}{|lcccccc|}
\hline Characteristic & $\mathbf{1}$ & $\mathbf{2}$ & $\mathbf{3}$ & $\mathbf{4}$ & $\mathbf{5}$ & $\mathbf{6}$ \\
\hline Growth on acetamide & + & - & - & $\mathrm{V}$ & $\mathrm{V}$ & $\mathrm{ND}$ \\
Denitrification & - & - & + & + & - & - \\
Assimilation of: & & & & & & \\
$\quad$ D-Glucose & - & - & + & - & - & + \\
D-Xylose & - & - & + & - & - & + \\
Mesaconate & + & - & + & $\mathrm{V}$ & + & $\mathrm{ND}$ \\
Aconitate & + & - & + & + & + & + \\
Diaminobutane & - & + & $\mathrm{ND}$ & $\mathrm{ND}$ & $\mathrm{V}$ & $\mathrm{ND}$ \\
& & & & & & \\
\end{tabular}

\section{Description of Achromobacter insolitus sp. nov.}

Achromobacter insolitus (in.so'li.tus. L. masc. adj. insolitus unusual, uncommon, referring to the fact that these organisms are found only rarely in human clinical samples).

Gram-negative, small (1-2 $\mu \mathrm{m}$ long) and coccoid cells that occur as a single unit, in pairs or in short chains. Motility is strain-dependent. On nutrient agar, colonies are flat or slightly convex with smooth margins and range from white to light brown in colour. Oxidase- and catalase-positive, but no urease, $\beta$-galactosidase or DNase activity is present. Nitrate reduction is present. Other biochemical characteristics are listed in the Results section above. In addition, Achromobacter insolitus grows on acetamide and assimilates isovalerate, malate, glutarate, DL-glycerate, mesaconate, aconitate, L-norleucine, L-valine, L-cysteine, L-tryptophan and tryptamine, but does not assimilate D-tartrate or diaminobutane. The following fatty acid components are present in significant amounts: $\mathrm{C}_{12: 0}, \mathrm{C}_{12: 0} 2-\mathrm{OH}, \mathrm{C}_{14: 0}$, $\mathrm{C}_{16: 0}, \mathrm{C}_{17: 0}$ cyclo, $\mathrm{C}_{18: 0}, \mathrm{Cl}_{8: 1} \omega 7 \mathrm{c}$ and summed features 2 and $3 . \mathrm{G}+\mathrm{C}$ content of the DNA is $64 \cdot 9-65 \cdot 5 \mathrm{~mol} \%$. Isolated from various human clinical samples.

The type strain, LMG $6003^{\mathrm{T}}$ (=API $201-3-84^{\mathrm{T}}=\mathrm{CCUG}$ $\left.47057^{\mathrm{T}}\right)$, was isolated from a leg wound. Characteristics of the type strain are the same as those for the species. In addition, the type strain assimilates $n$-caproate, pelargonate, caprate, L-tartrate, 2-ketoglutarate, benzoate, DL-norvaline, DL-2-aminobutyrate, L-tyrosine, L-lysine, $\beta$-alanine and DL-3-aminobutyrate. DNA G $+\mathrm{C}$ content of the type strain is $64.9 \mathrm{~mol} \%$.

\section{Description of Achromobacter spanius sp. nov.}

Achromobacter spanius (spa'ni.us. N.L. masc. adj. spanius from Gr. adj. spanios rare, scarce, referring to the fact that, so far, only a few strains have been found).
Gram-negative, small (1-2 $\mu \mathrm{m}$ long), coccoid cells that occur as a single unit, in pairs or in short chains. Motility is strain-dependent. On nutrient agar, colonies are flat or slightly convex with smooth margins and range from white to light brown in colour. Oxidase- and catalasepositive, but no urease, $\beta$-galactosidase or DNase activity is present. Nitrate reduction is present. Other biochemical characteristics are listed in the Results section above. In addition, Achromobacter spanius does not grow on acetamide, assimilates 2-ketoglutarate, L-tyrosine, $\beta$-alanine, DL-3-aminobutyrate, diaminobutane and tryptamine and does not assimilate mesaconate, aconitate, $n$-caproate, heptanoate, pelargonate, caprate, benzoate, p-hydroxybenzoate, glycine, L-methionine, L-ornithine, L-lysine, L-citrulline or DL-kynurenine. The following fatty acid components are present in significant amounts: $\mathrm{C}_{12: 0} 2-\mathrm{OH}$, $\mathrm{C}_{14: 0}, \mathrm{C}_{16: 0}, \mathrm{C}_{16: 0} 2-\mathrm{OH}, \mathrm{C}_{17: 0}$ cyclo, $\mathrm{C}_{18: 0}, \mathrm{C}_{18: 1} \omega 7 c$ and summed features 2 and $3 . \mathrm{G}+\mathrm{C}$ content of the DNA is $64 \cdot 9 \mathrm{~mol} \%$.

The type strain, LMG $5911^{\mathrm{T}}$ (=API $198-2-84^{\mathrm{T}}=$ CCUG $\left.47062^{\mathrm{T}}\right)$, was isolated from blood. Characteristics of the type strain are the same as those for the species. In addition, the type strain utilizes glutarate, DL-glycerate and L-tryptophan. DNA $\mathrm{G}+\mathrm{C}$ content of the type strain is $64 \cdot 9 \mathrm{~mol} \%$.

\section{Acknowledgements}

T.C. and P.V. are indebted to the Fund for Scientific Research Flanders (Belgium) for a position as postdoctoral fellow and research grants, respectively. T.C. also acknowledges support from the Belgian Federal Government (Federal Office for Scientific, Technical and Cultural Affairs). BCCM/LMG is supported by the Federal Office for Scientific, Technical and Cultural Affairs (Belgium).

\section{References}

Coenye, T., Falsen, E., Vancanneyt, M., Hoste, B., Govan, J. R. W., Kersters, K. \& Vandamme, P. (1999). Classification of Alcaligenes faecalis-like isolates from the environment and human clinical samples as Ralstonia gilardii sp. nov. Int J Syst Bacteriol 49, 405-413.

Coenye, T., Vancanneyt, M., Cnockaert, M., Falsen, E., Swings, J. \& Vandamme, P. (2003). Kerstersia gyiorum gen. nov., sp. nov., a novel Alcaligenes faecalis-like organism isolated from human clinical samples, and reclassification of Alcaligenes denitrificans Rüger and Tan 1983 as Achromobacter denitrificans comb. nov. Int J Syst Evol Microbiol 53, 1825-1831.

De Ley, J., Cattoir, H. \& Reynaerts, A. (1970). The quantitative measurement of DNA hybridization from renaturation rates. Eur $J$ Biochem 12, 133-142.

Ezaki, T., Hashimoto, Y. \& Yabuuchi, E. (1989). Fluorometric deoxyribonucleic acid-deoxyribonucleic acid hybridization in microdilution wells as an alternative to membrane filter hybridization in which radioisotopes are used to determine genetic relatedness among bacterial strains. Int J Syst Bacteriol 39, 224-229.

Foss, S., Heyen, U. \& Harder, J. (1998). Alcaligenes defragrans sp. nov., description of four strains isolated on alkenoic monoterpenes $((+)$-menthene, $\alpha$-pinene, 2 -carene, and $\alpha$-phellandrene) and nitrate. Syst Appl Microbiol 21, 237-244. 
Kersters, K. \& De Ley, J. (1984). Genus Alcaligenes Castellani and Chalmers 1919, 936 ${ }^{\mathrm{AL}}$. In Bergey's Manual of Systematic Bacteriology, vol. 1, pp. 361-373. Edited by N. R. Krieg \& J. G. Holt. Baltimore: Williams \& Wilkins.

Kersters, K., Hinz, K.-H., Hertle, A., Segers, P., Lievens, A., Siegmann, O. \& De Ley, J. (1984). Bordetella avium sp. nov., isolated from the respiratory tracts of turkeys and other birds. Int J Syst Bacteriol 34, 56-70.

Kiredjian, M., Holmes, B., Kersters, K., Guilvout, I. \& De Ley, J. (1986). Alcaligenes piechaudii, a new species from human clinial specimens and the environment. Int J Syst Bacteriol 36, 282-287.

Liu, L., Coenye, T., Burns, J. L., Whitby, P. W., Stull, T. L. \& LiPuma, J. J. (2002). Ribosomal DNA-directed PCR for identification of Achromobacter (Alcaligenes) xylosoxidans recovered from sputum samples from cystic fibrosis patients. J Clin Microbiol 40, 1210-1213.

Mesbah, M., Premachandran, U. \& Whitman, W. B. (1989). Precise measurement of the $\mathrm{G}+\mathrm{C}$ content of deoxyribonucleic acid by high-performance liquid chromatography. Int J Syst Bacteriol 39, 159-167.

National Committee for Clinical Laboratory Standards (1995). NCCLS Procedures, vol. 15, no. 14. Villanova, PA: NCCLS.

Pitcher, D. G., Saunders, N. A. \& Owen, R. J. (1989). Rapid extraction of bacterial genomic DNA with guanidium thiocyanate. Lett Appl Microbiol 8, 151-156.

Pot, B., Vandamme, P. \& Kersters, K. (1994). Analysis of electrophoretic whole-organism protein fingerprints. In Chemical Methods in Prokaryotic Systematics, pp. 493-521. Edited by M. Goodfellow \& A. G. J. O'Donnell. Chichester: Wiley.

Saitou, N. \& Nei, M. (1987). The neighbor-joining method: a new method for reconstructing phylogenetic trees. Mol Biol Evol 4, 406-425.

Stackebrandt, E. \& Goebel, B. M. (1994). Taxonomic note: a place for DNA-DNA reassociation and $16 \mathrm{~S}$ rRNA sequence analysis in the present species definition in bacteriology. Int $J$ Syst Bacteriol 44, 846-849.

Vancanneyt, M., Vandamme, P. \& Kersters, K. (1995). Differentiation of Bordetella pertussis, B. parapertussis, and B. bronchiseptica by whole-cell protein electrophoresis and fatty acid analysis. Int J Syst Bacteriol 45, 843-847.

Vandamme, P., Vancanneyt, M., Pot, B. \& 10 other authors (1992). Polyphasic taxonomic study of the emended genus Arcobacter with Arcobacter butzleri comb. nov. and Arcobacter skirrowii sp. nov., an aerotolerant bacterium isolated from veterinary specimens. Int J Syst Bacteriol 42, 344-356.

Vandamme, P., Gillis, M., Vancanneyt, M., Hoste, B., Kersters, K. \& Falsen, E. (1993). Moraxella lincolnii sp. nov., isolated from the human respiratory tract, and reevaluation of the taxonomic position of Moraxella osloensis. Int J Syst Bacteriol 43, 474-481.

Vandamme, P., Hommez, J., Vancanneyt, M., Monsieurs, M., Hoste, B., Cookson, B., Wirsing von König, C. H., Kersters, K. \& Blackall, P. J. (1995). Bordetella hinzii sp. nov., isolated from poultry and humans. Int J Syst Bacteriol 45, 37-45.

Vandamme, P., Heyndrickx, M., Vancanneyt, M., Hoste, B., De Vos, P., Falsen, E., Kersters, K. \& Hinz, K.-H. (1996). Bordetella trematum sp. nov., isolated from wounds and ear infections in humans, and reassessment of Alcaligenes denitrificans Rüger and Tan 1983. Int J Syst Bacteriol 46, 849-858.

Yabuuchi, E. \& Yano, I. (1981). Achromobacter gen. nov. and Achromobacter xylosoxidans (ex Yabuuchi and Ohyama 1971) nom. rev. Int J Syst Bacteriol 31, 477-478.

Yabuuchi, E., Kawamura, Y., Kosako, Y. \& Ezaki, T. (1998). Emendation of genus Achromobacter and Achromobacter xylosoxidans (Yabuuchi and Yano) and proposal of Achromobacter ruhlandii (Packer and Vishniac) comb. nov., Achromobacter piechaudii (Kiredjian et al.) comb. nov., and Achromobacter xylosoxidans subsp. denitrificans (Rüger and Tan) comb. nov. Microbiol Immunol 42, 429-438. 